\title{
Complementary supportive therapy for symptomatic patients with left ventricular dilatation and reduced ejection fraction
}

\section{(D) Mila Jakovljević ${ }^{*}$}

The Polyclinic for cardiovascular diseases and prevention Sveti Nikola, Korčula, Croatia
RECEIVED:

December 3, 2020

ACCEPTED:

December 18, 2020

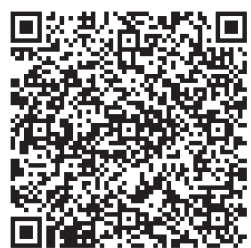

KEYWORDS: heart failure with reduced ejection fraction, metabolism, supportive therapy. CITATION: Cardiol Croat. 2021;16(1-2):23. | https://doi.org/10.15836/ccar2021.23

*ADDRESS FOR CORRESPONDENCE: Mila Jakovljević, Poliklinika za kardiovaskularne bolesti i prevenciju Sveti Nikola, Strećica 6, HR-20260 Korčula, Croatia. / Phone: +385-91-5142107 / E-mail: mila.jakovlj@gmail.com ORCID: Mila Jakovljević, https://orcid.org/0000-0002-1921-4098

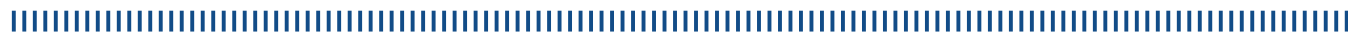

Introduction: The aim of the study was to assess the effect of complementary supportive therapy (CST) on the quality of life and functional capability in patients with heart failure and reduced ejection fraction (HFrEF).

Patients and Methods: We investigated 33 patients with left ventricular dilatation (LVIDd> $60 \mathrm{~mm}$ ) and reduced ejection fraction (EF $<40 \%$ ) in 76 complementary supportive therapy (CST) periods. Prior to each CST period, therapy was optimized (OMT) for one month. CST consists of a 10-day session. In addition to OMT, the patients were treated with carnitine, L-arginine, magnesium, thiamine, riboflavin, pantothenic acid, niacin, pyridoxal, biotin, lipoic acid, coenzyme Q-10, vitamin E, vitamin C, selenium while lying for 30 minutes inside a pulsating electromagnetic field with intensity up to 30 microteslas and inhaling negatively ionized oxygen. Before and after each CST period, patients were asked to evaluate the quality of life using the Minnesota Living with Heart Failure Questionnaire (MLHFQ) and the visual analogue scale and EF, LVIDd and NYHA classes were determined. Statistical analysis was based on the t-test, Spearman's rank correlation coefficient and Wilcoxon's signed-ranks test. The longest observation period was 122 months.

Results: After administering the complementary supportive therapy, a statistically significant improvement $(p<0.05)$ was noticed in the particular items of the MLHFQ, in emotional and physical dimensions. The values of VAS and EF increased whereas NYHA and LVIDd decreased significantly $(\mathrm{p}<0.001)$

Conclusion: CST significantly improved the quality of life and functional capacity in patients with HFrEF.1,2
LITERATURE IIIIIIIIIIIIIIIIIIIIIIIIIIIIIIIIIIIIIIIIIIIIIIIIIIIIIIIIIIIIIIIIIIIIIIIIIIIIIIIIIIIIIIIIIIIIIIIIIIIII

1. Doenst T, Nguyen TD, Abel ED. Cardiac metabolism in heart failure: implications beyond ATP production. Circ Res. 2013 Aug 30;113(6):709-24. https://doi.org/10.1161/CIRCRESAHA.113.300376

2 Gropper SS, Smith JL, Carr TP. Advanced Nutrition and Human Metabolism. $7^{\text {th }}$ edition. Cengage Learning. Boston, USA. 2018;401-51. 